Bull. Mater. Sci., Vol. 39, No. 6, October 2016, pp. 1483-1492. (c) Indian Academy of Sciences.

\title{
Metal oxide blended ZSM-5 nanocomposites as ethanol sensors
}

\author{
MADHURI LAKHANE ${ }^{1,2}$, RAJENDRA KHAIRNAR ${ }^{1}$ and MEGHA MAHABOLE ${ }^{1, *}$ \\ ${ }^{1}$ School of Physical Sciences, Swami Ramanand Teerth Marathwada University, Nanded (MS) 431606, India \\ ${ }^{2}$ Faculty of Mechanical Engineering, University of Maribor, Maribor 2000, Slovenia
}

MS received 20 August 2015; accepted 21 March 2016

\begin{abstract}
Nano-ZSM-5 is synthesized without organic template via microwave-assisted hydrothermal technique. The synthesized nano-ZSM-5 zeolite is blended with metal oxides $\left(\mathrm{ZnO}\right.$ and $\left.\mathrm{TiO}_{2}\right)$ to have novel composites as ethanol sensors. The composites are characterized by X-ray diffraction (XRD) and Fourier transform infrared (FTIR) techniques. A study on ethanol sensing behaviour of metal oxide blended composite screen-printed thick films is carried out and the effect of metal oxide concentration on various ethanol sensing features, specifically operating temperature, response/recovery time and active region of the sensor, are investigated. XRD and FTIR confirm the blending of metal oxides in $\mathrm{ZSM}-5$ matrix. Both, $\mathrm{ZnO}$ and $\mathrm{TiO}_{2}$ blended, composite films are sensitive to ethanol. It can be concluded that metal oxide blending improves the preformance of sensor for ethanol detection. The response/recovery time and active sensing regions depend upon the concentration of metal oxide in host zeolite. The $\mathrm{ZnO} / \mathrm{ZSM}-5$ and $\mathrm{TiO}_{2} / \mathrm{ZSM}-5$ composite films are the excellent ethanol sensors.
\end{abstract}

Keywords. ZSM-5 zeolite; composites; XRD; FTIR; ethanol sensing.

\section{Introduction}

Zeolite ZSM-5 $\left[\mathrm{Na}_{n} \mathrm{Al}_{n} \mathrm{Si}_{96-n} \mathrm{O}_{192} \cdot 16 \mathrm{H}_{2} \mathrm{O}(0<n<27)\right.$, abbreviated as Na-ZSM-5] is one of the most attractive members of high silica zeolite class. ZSM-5, a highly porous material, belongs to the pentasil family of zeolites with MFI framework [1]. Framework of ZSM-5 structure consists of intersecting 2D channel structure formed by 10 -membered oxygen rings. The main characteristic of this framework structure is the presence of straight channels with elliptical cross-section and zig-zag patterned channels with circular cross-section. It is the channel diameter that determines catalytic activity, selectivity and stability of zeolite ZSM-5 and hence it is considered as a significant catalyst [2]. Combination of the various novel properties like unique structure, molecular-sieving behaviour, excellent ion exchange capacity and adsorption capabilities along with excellent high thermal stability and chemical resistance makes the ZSM-5 zeolite very favourable for sensor applications [3,4]. Moreover, the porous nature of ZSM-5 gives rise to the high surface area, due to which it provides numerous sites for adsorption of molecules to be sensed [5-7]. It is reported in the literature that zeolites can be employed in sensor field either as a host material or as a filter or thin layer to enhance the sensing properties, especially semiconducting materials based sensors [8]. Literature review also indicates that the zeolite structure can be modified by incorporating various transition metals, cations and metal oxides as the

\footnotetext{
*Author for correspondence (mpmsrtmunsps@gmail.com, mahabolemegh@yahoo.co.in)
}

guest molecules, by serving as a host. These modifications, in turn, strongly influence diffusion, catalytic and especially adsorption properties of zeolite and consequently influence sensing applications. Hence, these host guest interactions may be used as the basis for sensing [9-11].

Semiconductors are the most attractive materials for gas sensor applications. Among various semiconducting metal oxides, zinc oxide $(\mathrm{ZnO})$ and titanium oxide $\left(\mathrm{TiO}_{2}\right)$ have attracted much attention because of their excellent electronic, chemical and optical properties. It is due to numerous features like cost effectiveness and flexibility in production, simplicity, ease in implementation, small size, quick response/recovery and high sensitivity, these semiconductors are widely used as gas sensors [12]. Moreover, these oxides exhibit high temperature stability, harsh environment tolerance and catalytic properties. These oxide-based sensors can be employed for the detection of low concentration of reducing as well as oxidizing gases and give fast response to a wide variety of gases [13-15]. It is also reported in the literature that addition of $\mathrm{TiO}_{2}$ to ZSM-5 leads to the increase in surface area [12].

Ethanol sensors, especially, have been the main focus of research in recent years for their applications in wide range of areas like chemical, biomedical and food industries, beverages quality monitoring, environmental monitoring, indoor air quality and breath analysis [16]. It is due to the great demand in diverse fields, that the search for new ethanol sensor materials is still needed. Literature survey reveals the sparseness in research based on metal oxide blended zeolite gas sensors.

Hence in this study, $\mathrm{ZnO}$ and $\mathrm{TiO}_{2}$ metal oxides are incorporated into ZSM-5 matrix to have the novel metal oxide/zeolite composites to meet the requirement of desired 
features, like high sensitivity, low working temperature and short response/recovery times for the ethanol sensor. The composite thick films, prepared by screen printing technique, are employed as the ethanol sensors and the effect of metal oxide concentration on ethanol sensing parameters is investigated.

\section{Experimental}

\subsection{Materials}

All the chemicals, used for synthesis of zeolite and fabrication of sensor, are of analytical grade purity and used without further purification. The raw materials used in this study, namely, sodium aluminate, sodium hydroxide, silica sol, titanium oxide $\left(\mathrm{TiO}_{2}\right)$, zinc oxide $(\mathrm{ZnO})$ and silica sol, are procured from Merck, India.

\subsection{Synthesis of Nano-ZSM-5 zeolite}

ZSM-5 zeolite crystals are synthesized via microwaveassisted template-free hydrothermal method as per the method described in literature to reduce the synthesis time [17]. Sodium aluminate (aluminium source), sodium hydroxide and silica sol (silica source) are used as the starting chemicals to obtain synthesis sol. Initially, solution is prepared by dissolving simultaneously appropriate amounts of sodium hydroxide $(4.0 \mathrm{~g})$ and sodium aluminate $(1.64 \mathrm{~g})$ in $135 \mathrm{ml}$ of deionized water. Silica sol (104 g) is slowly added to the solution under a condition of constant and vigorous stirring. Addition of silica sol immediately results in the formation of a white gel. The gel solution, thus formed, is further magnetically stirred for $5 \mathrm{~h}$ and later on aged for $24 \mathrm{~h}$ at room temperature for the first-order nucleation.

Prior to being transferred to a stainless steel autoclave, the aged gel is then exposed to microwave radiations for $5 \mathrm{~min}$ to expedite the crystallization process and then transferred to autoclave. Finally, it is hydrothermally treated for variable time durations $(20,18,15$ and $12 \mathrm{~h})$ at $453 \mathrm{~K}$ temperature in order to optimize crystallization period. After the completion of the reaction and series of experiments, the obtained products are air-cooled to room temperature. These products are further thoroughly washed with deionized water and filtered. All the obtained products are then dried at $373 \mathrm{~K}$ for $24 \mathrm{~h}$ and sintered at $773 \mathrm{~K}$ for $2 \mathrm{~h}$. Synthesis protocol is presented in figure 1 .

\subsection{Preparation of metal oxide blended sensors}

The main raw materials used for the sample preparation are zeolite and metal oxides. ZSM-5 zeolite is used as the host matrix and three different kinds of metal oxides are employed as the reinforcing guest molecules. The particle reinforced composites are prepared using nanoparticles of Merck grade metal oxides, namely, $\mathrm{ZnO}, \mathrm{TiO}_{2}$ and $\mathrm{CuO}$ with 25,50 and $75 \%$ weight content of ZSM-5 zeolite using a simple physical mixture method. The ingredients are thoroughly dry mixed mechanically, using agate mortar, for about $10 \mathrm{~h}$ to have homogeneous admixtures and to ensure dispersion of metal oxides in zeolite at different concentrations.

\subsection{Preparation of thick film sensors}

The preparation of thick film sensor is as per the process reported earlier [18]. In brief, appropriate amount of prepared metal oxide/ZSM-5 composite is mixed and grounded with adhesive materials in an agate mortar to form a glutinous paste. The paste is then coated onto surface of precleaned glass substrate by using screen printing technique to obtain thick films. Coated films are dried under IR lamp for $20 \mathrm{~min}$ followed by final sintering at $650^{\circ} \mathrm{C}$ for about $2 \mathrm{~h}$ for ensuring

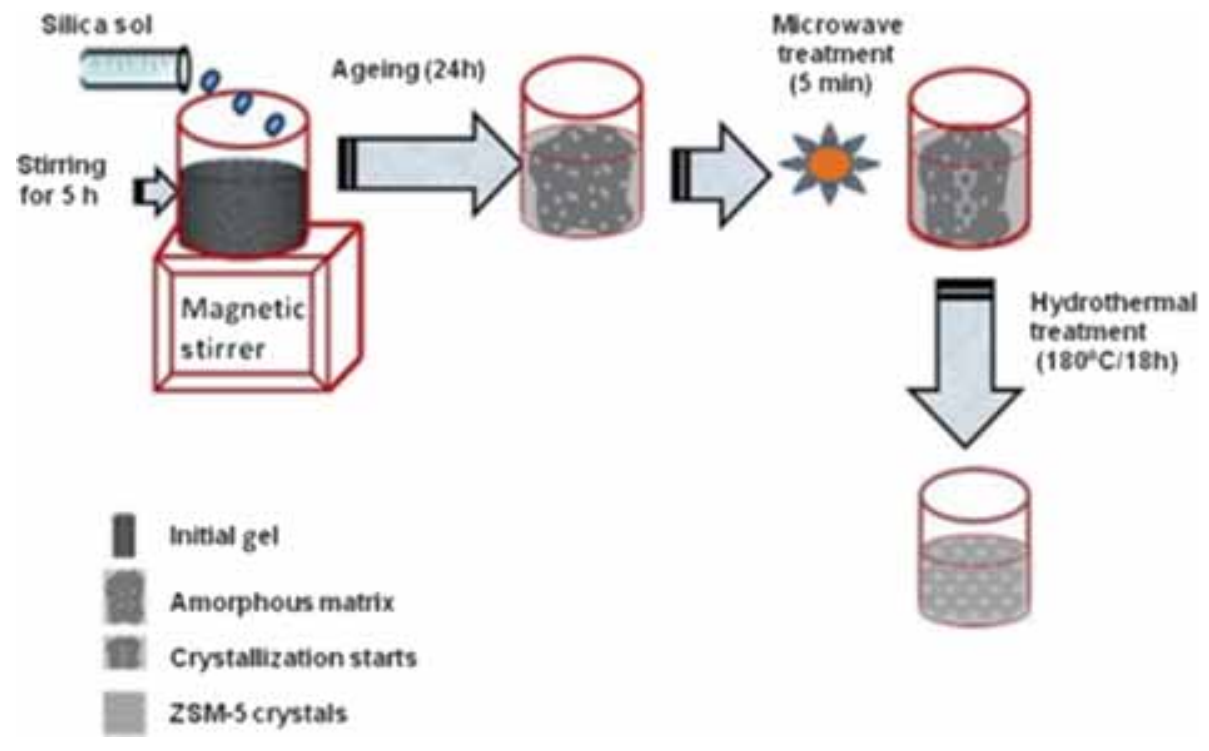

Figure 1. The synthesis protocol showing the growth process of nano-ZSM-5 zeolite. 
proper adhesion of film. These films, thus prepared, are used to detect ethanol vapours.

\subsection{Characterization}

The crystallinity of the sintered ZSM-5 and metal oxide/ ZSM-5 composites is verified by means of Rigaku-make $\mathrm{X}$-ray diffractometer with $\mathrm{Cu}-\mathrm{K} \alpha$ radiation $(1.54014 \AA)$. The $\mathrm{X}$-ray diffraction (XRD) peaks are recorded in the $2 \theta$ range of 5-60 degrees. Fourier transform infrared (FTIR) spectra of the ZSM-5 and prepared composite samples are recorded by means of $\mathrm{KBr}$ pellet technique in the FTIR scan range 4000$400 \mathrm{~cm}^{-1}$ with a resolution of $4 \mathrm{~cm}^{-1}$ using Shimadzu-make FTIR spectrophotometer.

\subsection{Sensor performance testing method}

Ethanol sensing performance of each developed sensor is tested by using a home-made static gas test unit. Briefly, the sensor is heated with the help of heater from room temperature to $350^{\circ} \mathrm{C}$ and sensor resistance is measured in air at an interval of $5^{\circ} \mathrm{C}$ temperature. Later on a fixed amount of ethanol (in p.p.m.) is injected into the test chamber through a gas inlet valve by using the syringe to have an ethanol vapour-air mixture followed by the measurement of resistance with respect to change in temperature. The sensing characteristics of the each sensor are determined by measuring the change in electrical resistance of the sensor film in air $\left(R_{\mathrm{a}}\right)$ and in ethanol vapour-air mixture $\left(R_{\mathrm{g}}\right)$. The response to ethanol/sensitivity is calculated using the following equation [19]:

$$
S(\%)=\frac{R_{\mathrm{g}}-R_{\mathrm{a}}}{R_{\mathrm{a}}} \times 100,
$$

where $R_{\mathrm{a}}$ is the resistance of sensor in air and $R_{\mathrm{g}}$ the resistance of sensor after ethanol exposure. The change in sensitivity of the film is plotted as a function of temperature and operating temperature is determined corresponding to a maximum sensitivity. The maximum ethanol uptake capacity of the sensor film is determined by exposing the film to variable ethanol concentrations (p.p.m.) and simultaneously measuring the change in resistance (sensitivity) as a function of variable ethanol concentration (p.p.m.). The time taken by the sensor to respond to a fixed ethanol vapour concentration (response time) and to regain its original state upon exposure to air (recovery time) are determined by exposing each composite film to air and fixed concentration of ethanol vapour-air mixture alternately.

\section{Results and discussion}

\subsection{XRD studies}

The XRD profiles of $\mathrm{ZnO}$ blended ZSM-5 composites are presented in figure $2 \mathrm{~A}(\mathrm{a}-\mathrm{d})$, wherein the XRD profile of pure ZSM-5 is considered as a reference. Figure $2 \mathrm{~A}(\mathrm{a})$ reveals the presence of peaks corresponding to ZSM-5 zeolite structure
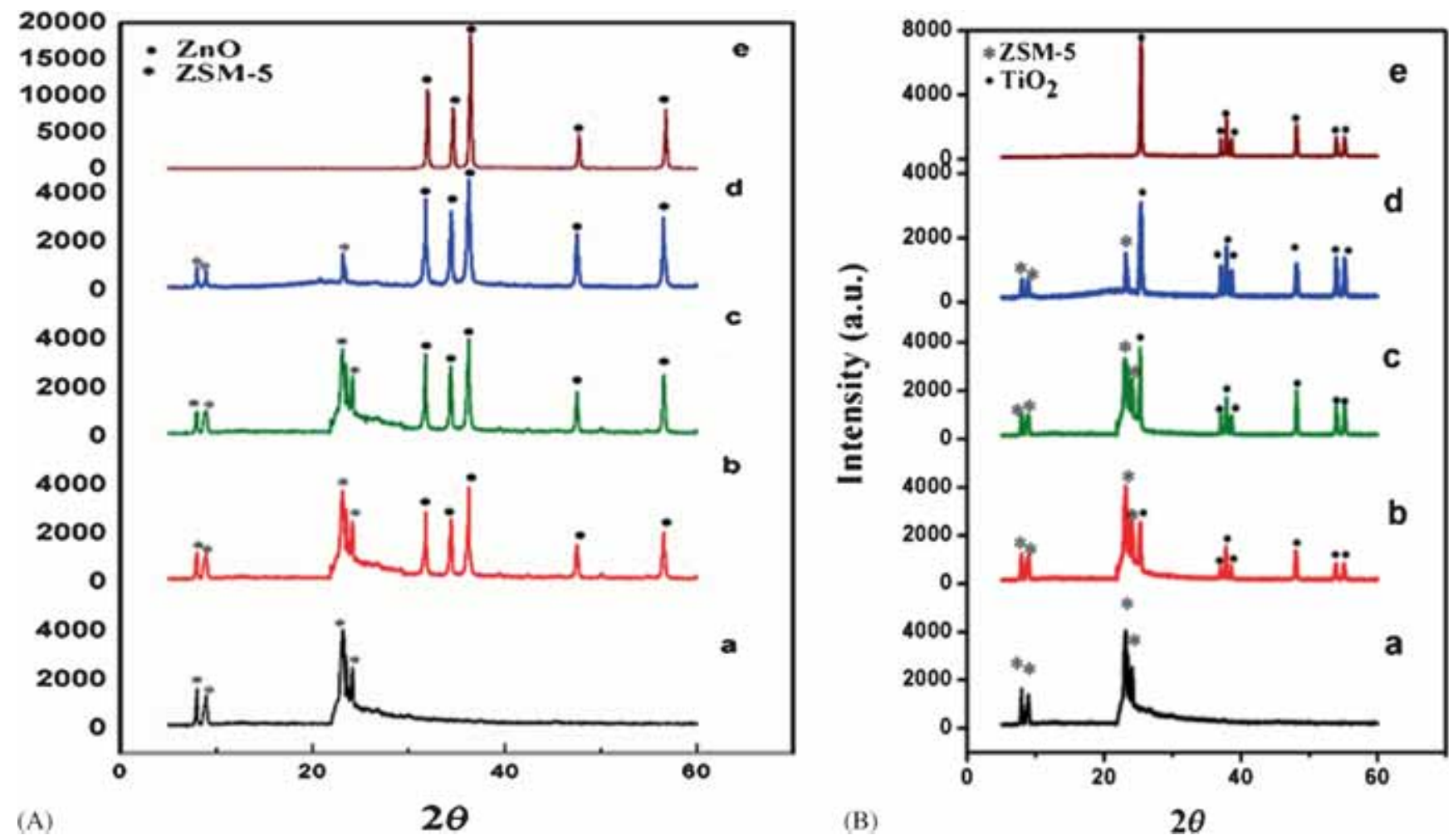

Figure 2. (A and B) Powder XRD patterns showing the presence of characteristic peaks of ZSM-5, ZnO and TiO 2 : (a) pure ZSM-5; (b) $25 \%$ metal oxide, (c) $50 \%$ metal oxide, (d) $75 \%$ metal oxide and (e) pure metal oxide. 
[20]. The blending of $\mathrm{ZnO}$ with ZSM-5 zeolite host matrix can be visualized, from figure $2 \mathrm{~A}(\mathrm{~b}-\mathrm{d})$, by the presence characteristic peaks of zinc oxide corresponding to (100), (002), (101), (102) and (110) planes. The phase analysis, carried out as per JCPDS card (36-1451), confirms the wurtzite-type hexagonal structure of $\mathrm{ZnO}$. The intensities of $\mathrm{ZnO}$ planes are found to be increasing with increase in $\mathrm{ZnO}$ concentration in a composite. It is observed that the intensities of typical ZSM-5 peaks remain unaltered up to $50 \% \mathrm{ZnO}$ contribution. However, for higher $\mathrm{ZnO}$ concentration (75\%), sudden decrease in intensity is observed which indicates the dominance of $\mathrm{ZnO}$ in zeolite matrix. Moreover, sharp diffraction peaks apparent in all XRD profiles show good crystallinity of the pure as well as composite samples, and there are almost no changes in crystallinity of the zeolite composites.

Similar kind of behaviour is observed for $\mathrm{TiO}_{2}$ blended ZSM-5 composites. Figure $2 \mathrm{~B}(\mathrm{a}-\mathrm{d})$ presents the XRD patterns for $\mathrm{TiO}_{2}$ blended $\mathrm{ZSM}-5$ zeolites as a function of $\mathrm{TiO}_{2}$ concentration with that for pure ZSM-5 as the base. The XRD pattern shown in figure $2 \mathrm{~B}(\mathrm{a})$ agrees well with that reported in the literature for ZSM-5 zeolite [21]. The presence of $\mathrm{TiO}_{2}$ peaks near $2 \theta$ values of $25.28,37.9,48.2,53.8$ and 55.2 degrees correspond to the anatase phase (JCPDS file no. 21-1272), as depicted in figure 2e. Figure $2 B(b-d)$ reveals the presence of typical XRD peaks of host ZSM-5 matrix as well as reinforcing $\mathrm{TiO}_{2}$. It can be seen from figure $2 \mathrm{~B}(\mathrm{~b}-\mathrm{d})$ that as the concentration of $\mathrm{TiO}_{2}$ in composite increases, doublet nature of ZSM-5 peaks, appearing between 23 and $24^{\circ}$, changes to singlet and intensities for all ZSM-5 peaks decrease. Increase in $\mathrm{TiO}_{2}$ concentration leads to increase in intensities of almost all peaks related to $\mathrm{TiO}_{2}$ in all composite samples.

Thus, it can be concluded that XRD profiles of metal oxide blended ZSM-5 zeolite composite samples show their typical XRD peaks corresponding to $\mathrm{ZnO}, \mathrm{TiO}_{2}$ and $\mathrm{ZSM}-5$ host. No new phase structure is detected. This indicates that the metal oxide particulates are scattered uniformly in the zeolite matrix and the blending of metal oxides do not destroy the structure of the zeolite.

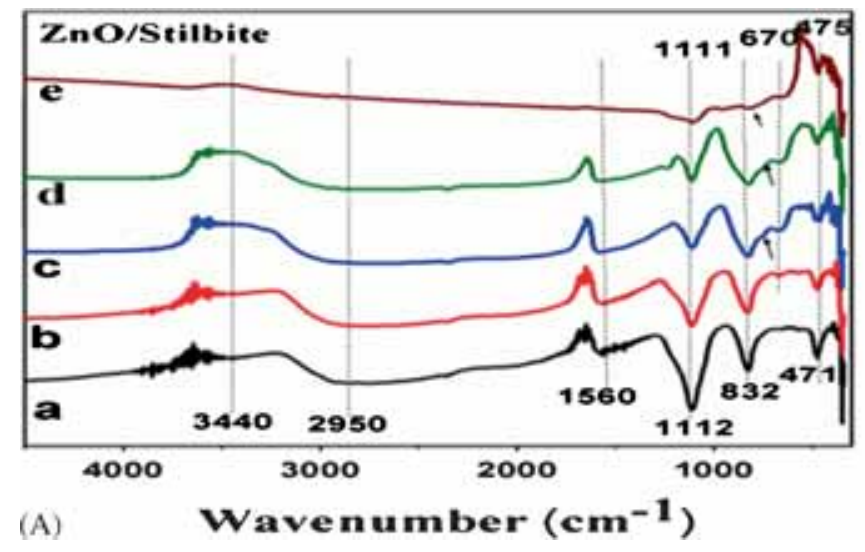

\subsection{FTIR spectroscopy}

Figure $3 \mathrm{~A}(\mathrm{a}-\mathrm{d})$ shows the typical FTIR spectra of $\mathrm{ZnO} /$ ZSM-5 composites as a function of $\mathrm{ZnO}$ concentration and are compared with that of pure ZSM-5. The spectrum of pure ZSM-5 (figure 3A(a)) reveals the presence of typical bands corresponding to vibrations of tetrahedral and framework atoms in zeolite structure. The absorption peak at $482 \mathrm{~cm}^{-1}$ can be attributed to bending vibrations of $\mathrm{Si}-\mathrm{O}-\mathrm{Si}$ bonds. The presence of this peak at $482 \mathrm{~cm}^{-1}$ confirms the characteristic of five-membered ring pentasil structure of ZSM-5. A broad peak near $701 \mathrm{~cm}^{-1}$ can be assigned to external symmetric stretching vibrations of $\mathrm{Si}-\mathrm{O}$ group [22]. The absorption bands present at 898 and $1111 \mathrm{~cm}^{-1}$ are attributed to external symmetric and internal asymmetric stretching vibrations of $\mathrm{Si}-\mathrm{O}-\mathrm{Si}$ bonds [20]. The structure sensitive absorption band (a small shoulder peak), attributed to asymmetric vibration of $\mathrm{T}-\mathrm{O}$ bond corresponding to external linkages between $\mathrm{TO}_{4}$ tetrahedra, is observed to be present at $1220 \mathrm{~cm}^{-1}$ [23]. This peak is found to be disappearing for higher $\mathrm{ZnO}$ concentration (75\%). The presence of weak band near $1590 \mathrm{~cm}^{-1}$ corresponds to bending vibrations of adsorbed water molecules [22].

The IR spectrum of pure zinc oxide (figure $3 \mathrm{~A}(\mathrm{e})$ ) includes bands at 470 and $1111 \mathrm{~cm}^{-1}$. The band centred at $470 \mathrm{~cm}^{-1}$ is due to the vibrations of $\mathrm{Zn}-\mathrm{O}$ stretching modes. In the IR spectra of composites (figure $3 \mathrm{~A}(\mathrm{~b}-\mathrm{d})$ ), decrease in intensities of absorption bands at 482,898 and $1111 \mathrm{~cm}^{-1}$ attributed to ZSM-5 with increase in $\mathrm{ZnO}$ concentration. In case of composites, the peaks at 482 and $898 \mathrm{~cm}^{-1}$ shift towards lower wavenumber side, i.e., at 470 and $860 \mathrm{~cm}^{-1}$, respectively. The characteristic feature of these spectra, compared with the spectra of pure ZSM-5 and $\mathrm{ZnO}$, is the splitting of a broadband at $701 \mathrm{~cm}^{-1}$ into doublet peaks. The emergence of new peak at $670 \mathrm{~cm}^{-1}$ is related to stretching vibrations of $\mathrm{Zn}-\mathrm{O}$ bond [24] and peak at $701 \mathrm{~cm}^{-1}$ shifts at higher energy side. Moreover, the intensity of these doublet peaks also decreases with increase in the concentration of zinc oxide in the composites, while broadening the peaks. For the higher

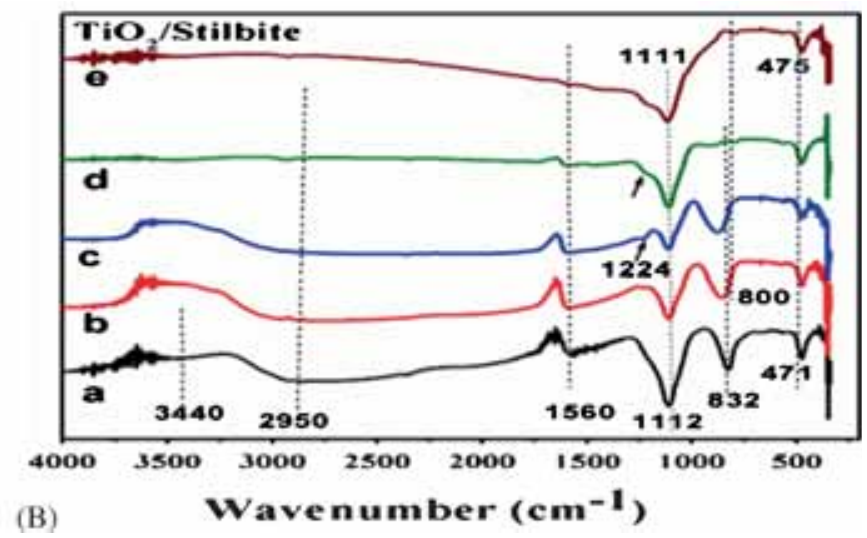

Figure 3. (A and B) Typical FITR spectra of ZnO/ZSM-5 and TiO2/ZSM-5 composites depicting the existence of structure sensitive and insensitive absorption bands corresponding to various functional groups due to typical zeolite structure, $\mathrm{ZnO}$ and $\mathrm{TiO}_{2}$; (a) pure $\mathrm{ZSM}-5$; (b) $25 \%$ metal oxide; (c) $50 \%$ metal oxide (d) $75 \%$ metal oxide and (e) pure metal oxide. 
$\mathrm{ZnO}$ concentration, a small shoulder peak is observed at $908 \mathrm{~cm}^{-1}$ which is also the characteristic peak of $\mathrm{ZnO}$ [25].

Figure 3B(a-e) displays FTIR spectra for pure ZSM-5 and $\mathrm{TiO}_{2} / Z \mathrm{ZM}-5$ composites and pure $\mathrm{TiO}_{2}$. The FTIR spectrum, showing unique adsorption peaks corresponding to ZSM-5 structure, is considered as a reference. The spectrum of pristine titanium oxide (figure $3 \mathrm{e}$ ) reveals the presence of absorption peaks at 475, 800 and $1111 \mathrm{~cm}^{-1}$. The bands at 475 and $1111 \mathrm{~cm}^{-1}$ are due to Ti-O-Ti framework bonds [26]. The peak observed at $800 \mathrm{~cm}^{-1}$ can be attributed to symmetric stretching vibration of Ti-O bonds in $\mathrm{TiO}_{2}$ lattice [27].

In the case of $\mathrm{TiO}_{2} / \mathrm{ZSM}-5$ composite, inclusion of titanium oxide can be confirmed by the appearance of a new shoulder peak at $800 \mathrm{~cm}^{-1}$. The unique ZSM-5 peak present at $880 \mathrm{~cm}^{-1}$ shifts to higher frequency side and the peak at $1111 \mathrm{~cm}^{-1}$ slightly shifts towards low frequency. The peak occurring at $1280 \mathrm{~cm}^{-1}$, assigned to asymmetric vibration of $\mathrm{T}-\mathrm{O}$ bond corresponding to external linkages between $\mathrm{TO}_{4}$ tetrahedra, is observed in all samples. However, peak near $1590 \mathrm{~cm}^{-1}$, corresponding to bending vibrations of adsorbed water molecules, is also present in all FTIR spectra of composites. The intensity of absorption peak, occurring at $1109 \mathrm{~cm}^{-1}$, is found to be decreasing with increase in
$\mathrm{TiO}_{2}$ concentration and a broad absorption band at $704 \mathrm{~cm}^{-1}$ disappears.

\subsection{Ethanol sensing performance of the composite films}

3.3a Operating temperature and ethanol response: Figure 4A and $\mathrm{B}$ shows the repeatability and reproducibility behaviour of metal oxide blended ZSM-5 composite sensors. Response to a fixed concentration of ethanol (100 p.p.m.) for $\mathrm{ZnO} / \mathrm{ZSM}-5$ films is depicted in figure 5a. Response to ethanol vapours by all composite film sensors shows a general trend, wherein the response to ethanol vapours goes on increasing with operating temperature and it reaches to a maximum value for a particular temperature. It decreases for further increase of operating temperature. It is also observed that the response decreases with the increase in subsequent trials, except for $50 \% \mathrm{ZnO}$ concentration. These graphs indicate that the operating temperature for composite sensors, corresponding to maximum response, is a function of $\mathrm{ZnO}$ concentration. The ZnO/ZSM-5 composite film with $25 \%$ $\mathrm{ZnO}$ concentration is operated at comparatively lower opeating temperature $\left(90^{\circ} \mathrm{C}\right)$, as compared to sensors with 50 and $75 \% \mathrm{ZnO}$ concentrations. It is further observed that for
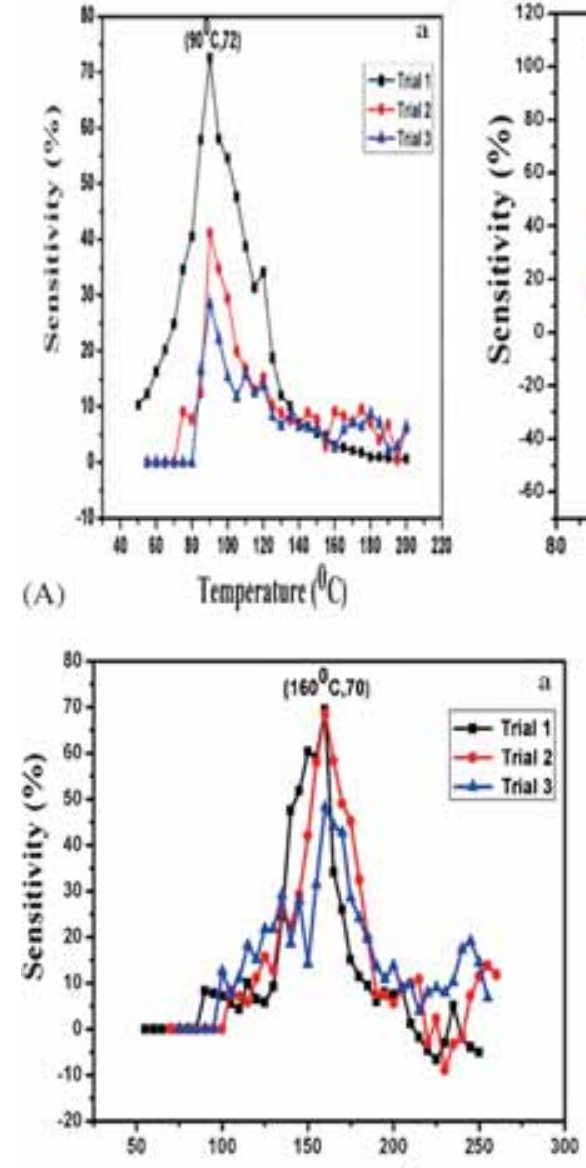

(B)
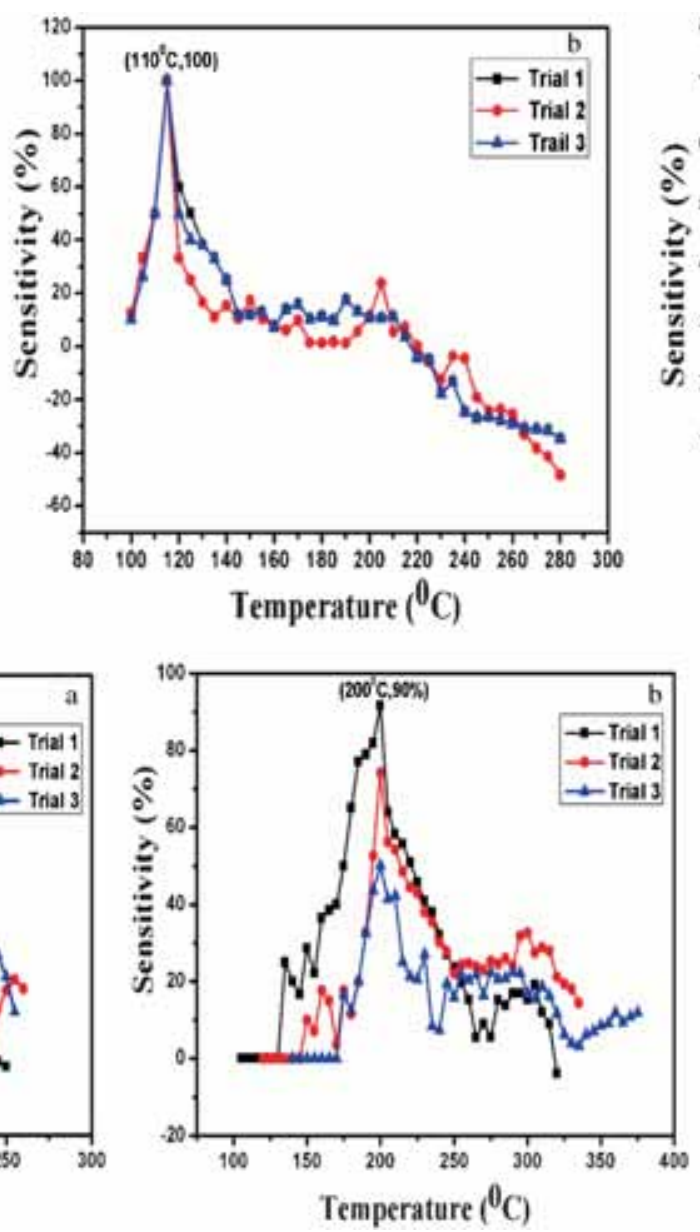
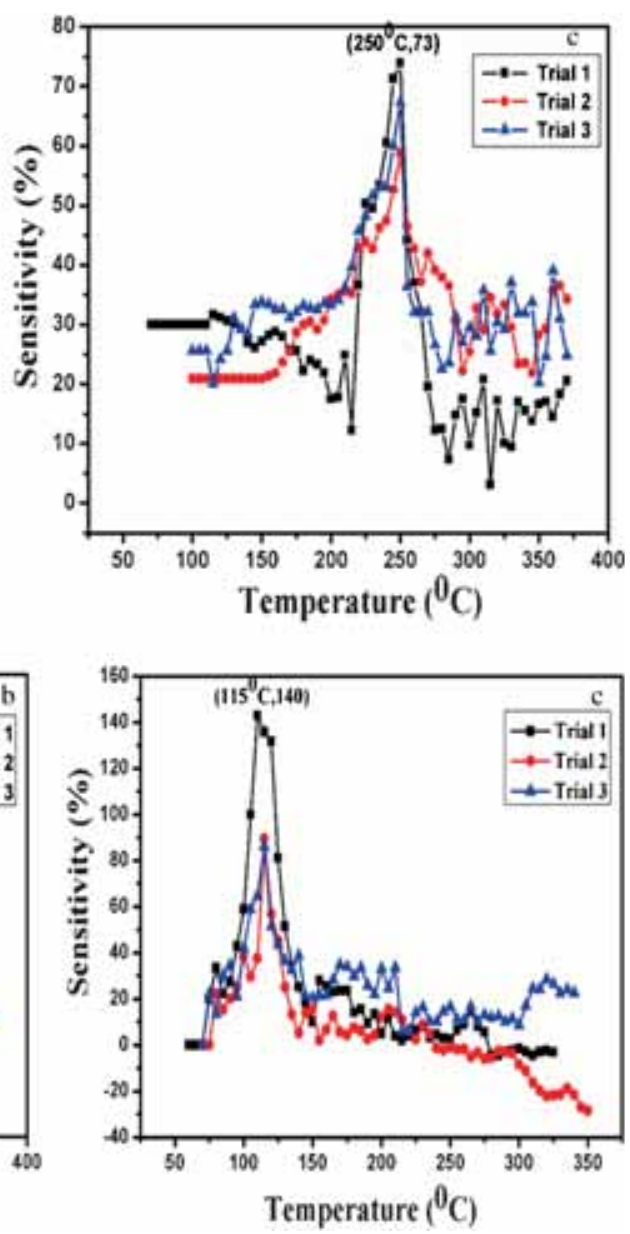

Figure 4. (A and $\mathbf{B}$ ) Repeatability tests for $\mathrm{ZnO} / \mathrm{ZSM}-5$ and $\mathrm{TiO}_{2} / \mathrm{ZSM}-5$ composite thick films showing the trend of change in sensitivity as a function of temperature: (a) $25 \%$ metal oxide, (b) $50 \%$ metal oxide and (c) $75 \%$ metal oxide. 
higher $\mathrm{ZnO}$ concentration $(75 \%)$, the operating temperature shifts to higher temperature $\left(160^{\circ} \mathrm{C}\right)$.

Temperature dependence of the ethanol response of $\mathrm{TiO}_{2} / \mathrm{ZSM}-5$ composite thick films is shown in figure $5 \mathrm{~b}$. The plots show similar kind of variation in ethanol response for all $\mathrm{TiO}_{2}$ concentrations. The behaviour consists of increase in ethanol response with operating temperature, reaching to a maximum value followed by decrease in response with further increase in operating temperature. The operating temperature shows typical behaviour with respect to $\mathrm{TiO}_{2}$ concentration. It changes from $160^{\circ} \mathrm{C}$ for $25 \%$ to $200^{\circ} \mathrm{C}$ for $50 \%$ and then suddenly shifts to $115^{\circ} \mathrm{C}$ for still higher concentration of $75 \%$. The study reveals that there is a strong influence of concentration of reinforcing material on operating temperature of blended ZSM-5 sensor matrix.

$3.3 \mathrm{~b}$ Active region: Figure $6 \mathrm{a}$ and $\mathrm{b}$ shows the change in ethanol response as a function of ethanol concentration for ZSM-5 and ZnO/ZSM-5 thick films held at their respective operating temperatures. The response increases rapidly in the lower concentration region of ethanol, while it increases gradually at higher concentrations of ethanol. It finally achieves a constant value for still higher ethanol concentration. The active region of the sensor is defined as
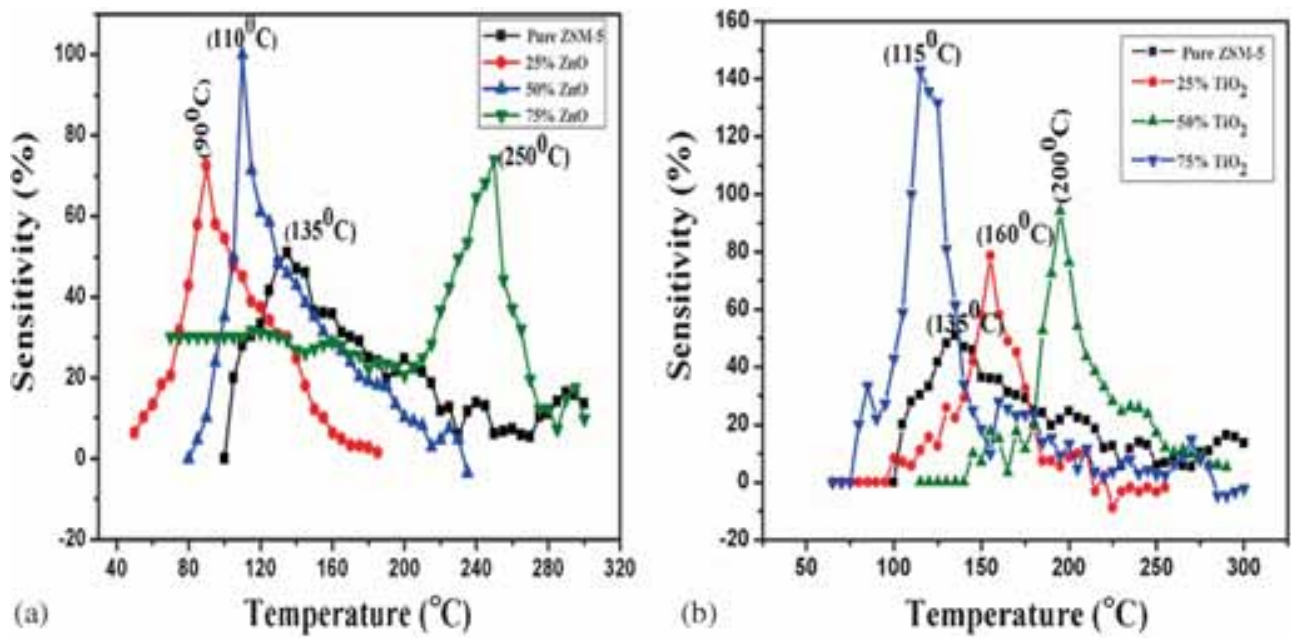

Figure 5. Comparative ethanol sensing behaviour of pure and metal oxide blended ZSM-5 composite thick film sensors showing the typical variation in operating temperature and sensitivity as a function of temperature: (a) $\mathrm{ZnO} / \mathrm{ZSM}-5$ and (b) $\mathrm{TiO}_{2} / \mathrm{ZSM}-5$.
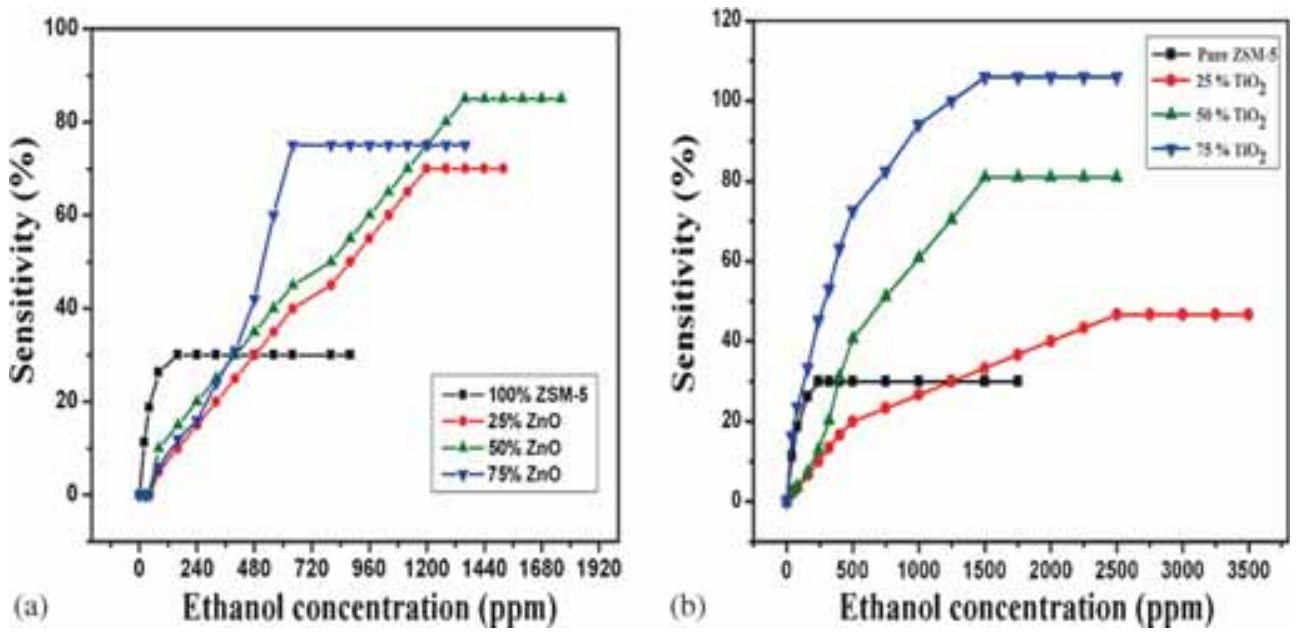

Figure 6. Comparative nature of ethanol uptake capacities of pure and metal oxide blended ZSM-5 composite thick film sensors as a function of ethanol vapour concentration. (a) ZnO/ZSM-5 at corresponding operating temperatures $\left(90,11\right.$ and $250^{\circ} \mathrm{C}$ ) for 25,50 and $75 \%$ of $\mathrm{ZnO}$, respectively, and (b) $\mathrm{TiO}_{2} / \mathrm{ZSM}-5$ at corresponding operating temperatures $\left(160,200\right.$ and $\left.115^{\circ} \mathrm{C}\right)$ for 25,50 and 75 of $\mathrm{TiO}_{2}$, respectively. 
the range of ethanol concentration from particular minimum to maximum (p.p.m.) to which it can give response. Thus, the active regions for these composite sensors are found to be from 10 to 1200,1360 and 640 p.p.m. at operating temperatures 90,110 and $250^{\circ} \mathrm{C}$ for 25,50 and $75 \% \mathrm{ZnO}$ concentrations, respectively.

In the case of $\mathrm{TiO}_{2} / \mathrm{ZSM}-5$ films, enhancement in ethanol sensing capability of sensor is observed and is depicted in figure $6 \mathrm{~b}$. However, the range of active region decreases with increase in $\mathrm{TiO}_{2}$ concentration. The sensor with lowest $\mathrm{TiO}_{2}$ concentration (25\%) can sense the ethanol up to 2500 p.p.m. at an operating temperature $160^{\circ} \mathrm{C}$. However, for higher concentrations ( 50 and $75 \%$ of $\mathrm{TiO}_{2}$ ), the ethanol uptake capacity for the sensor remains constant (1500 p.p.m.) at corresponding operating temperatures 200 and $115^{\circ} \mathrm{C}$, respectively.

3.3c Response/recovery behaviour: Figure 7a presents the variation in response/recovery time for $\mathrm{ZnO} / \mathrm{ZSM}-5$ composite sensors as a function of $\mathrm{ZnO}$ concentration. It is clearly found that as the concentration of reinforcing $\mathrm{ZnO}$ increases, the corresponding composite film gives faster response upon exposure to ethanol and shows speedy recovery after exposing it to air.

The change in ethanol response as a function of time for $\mathrm{TiO}_{2} / \mathrm{ZSM}-5$ sensors is shown in figure $7 \mathrm{~b}$. It is observed that all composite films give quick response to ethanol compared to that by pure ZSM-5 film sensor $\left(150 \mathrm{~s}\right.$ at $\left.135^{\circ} \mathrm{C}\right)$. The composite film with $25 \% \mathrm{TiO}_{2}$ concentration results in quick response $\left(10 \mathrm{~s}\right.$ at $\left.160^{\circ} \mathrm{C}\right)$, but takes longer time (200 s) to get recovered. The recovery time is found to be the lowest for $75 \mathrm{wt} \% \mathrm{TiO}_{2}\left(30 \mathrm{~s}\right.$ at $\left.115^{\circ} \mathrm{C}\right)$.

Figure 8A and $\mathrm{B}$ depicts the response/recovery transients for $\mathrm{ZnO} / \mathrm{ZSM}-5$ and $\mathrm{TiO}_{2} / \mathrm{ZSM}-5$ composite sensors towards the ethanol vapours at respective working temperatures for variable concentration of ethanol. The $\mathrm{ZnO} / \mathrm{ZSM}-5$ composites with 25,50 and $75 \% \mathrm{ZnO}$ concentrations are operated
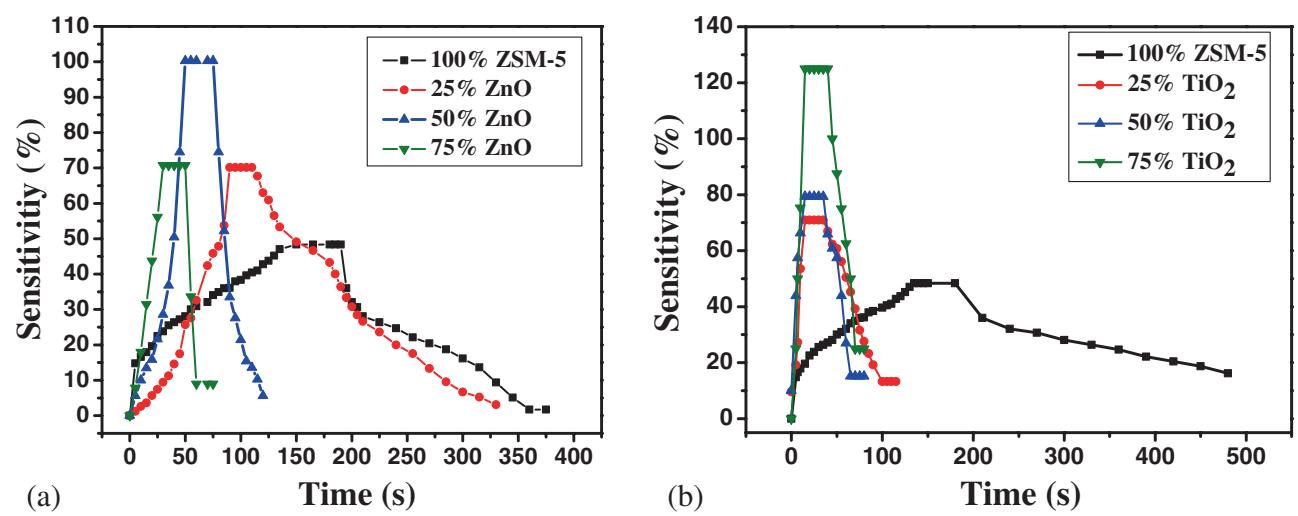

Figure 7. (a and b) Comparison of response and recovery behaviors of pure and metal oxide blended ZSM-5 composite thick film sensors as a function of time revealing the effect of metal oxide concentration. (a) $\mathrm{ZnO} / \mathrm{ZSM}-5$ at corresponding operating temperature $\left(90,110,250^{\circ} \mathrm{C}\right.$ ) for $25,50,75 \%$ of $\mathrm{ZnO}$, respectively, and (b) $\mathrm{TiO}_{2} / \mathrm{ZSM}-5$ at corresponding operating temperature $\left(160,200,115^{\circ} \mathrm{C}\right)$ for 25,50 , $75 \%$ of $\mathrm{TiO}_{2}$, respectively.
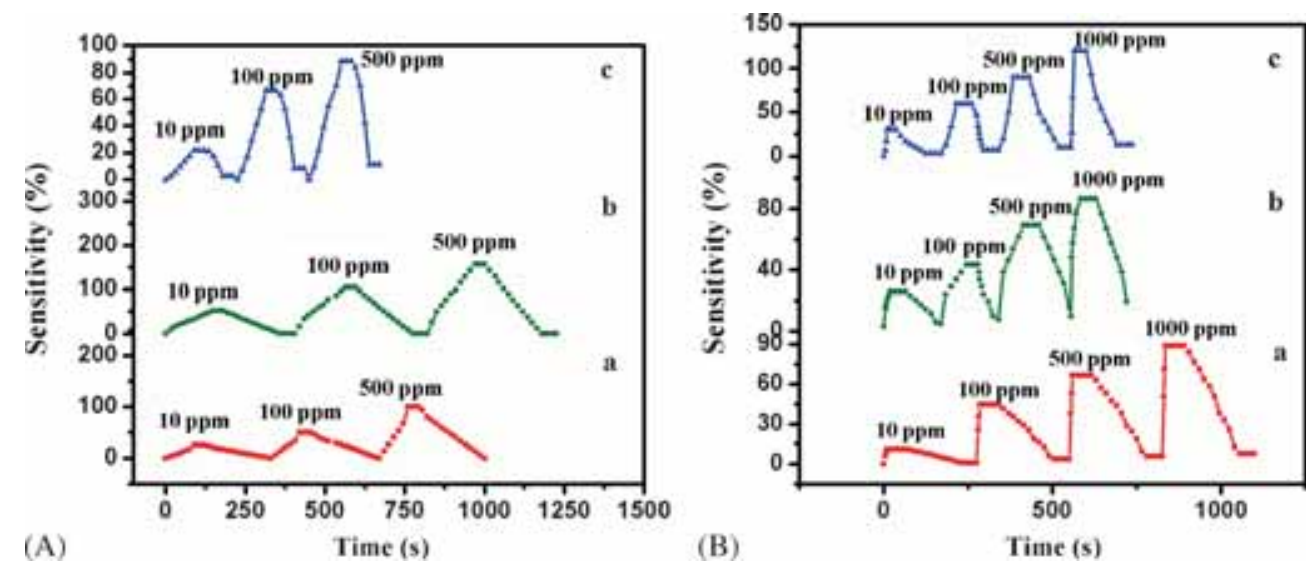

Figure 8. (A and B) Ethanol sensitivity of metal oxide blended ZSM-5 composite sensors upon exposure to ethanol at their respective operating temperatures demonstrating an increase in sensitivity with increase in ethanol concentration (A) ZnO/ZSM-5 at corresponding operating temperatures (90, $\left.110,250^{\circ} \mathrm{C}\right)$ for $25,50,75 \%$ of $\mathrm{ZnO}$, respectively, and $(\mathbf{B}) \mathrm{TiO}_{2} / \mathrm{ZSM}-5$ at corresponding operating temperature $\left(160,200,115^{\circ} \mathrm{C}\right)$ for $25,50,75 \%$ of $\mathrm{TiO}_{2}$, respectively. 
Table 1. The ethanol sensing parameters of pure and ZSM-5 composite thick film sensors.

\begin{tabular}{|c|c|c|c|c|c|c|c|}
\hline \multirow[b]{2}{*}{ Materials } & \multirow[b]{2}{*}{ Pure ZSM-5 } & \multicolumn{3}{|c|}{$\mathrm{ZSM}-5+\mathrm{ZnO}$} & \multicolumn{3}{|c|}{$\mathrm{ZSM}-5+\mathrm{TiO}_{2}$} \\
\hline & & $25 \% \mathrm{ZnO}$ & $50 \% \mathrm{ZnO}$ & $75 \% \mathrm{ZnO}$ & $25 \% \mathrm{TiO}_{2}$ & $50 \% \mathrm{TiO}_{2}$ & $75 \% \mathrm{TiO}_{2}$ \\
\hline Operating temperature $\left({ }^{\circ} \mathrm{C}\right)$ & 135 & 90 & 110 & 250 & 160 & 200 & 115 \\
\hline Ethanol sensitivity $(\%)$ & 50 & 72 & 100 & 75 & 70 & 97 & 140 \\
\hline Saturation (p.p.m.) & 160 & 1200 & 1360 & 640 & 2500 & 1500 & 1500 \\
\hline Response time (s) & 150 & 105 & 50 & 30 & 10 & 15 & 15 \\
\hline Recovery time (s) & 180 & 185 & 60 & 30 & 200 & 80 & 30 \\
\hline
\end{tabular}

at 90,110 and $250^{\circ} \mathrm{C}$, respectively. Likewise for 25,50 and $75 \% \quad \mathrm{TiO}_{2}$ concentrations, $\mathrm{TiO}_{2} / \mathrm{ZSM}-5$ composites are operated at 160,200 and $115^{\circ} \mathrm{C}$, respectively. The typical $\mathrm{ZnO} / \mathrm{ZSM}-5$ sensor with $25 \% \mathrm{ZnO}$ concentration (figure $8 \mathrm{~A}(\mathrm{a})$ ) shows response of the order of 25,50 and 100 for 10,100 and 500 p.p.m. concentrations of ethanol vapours, respectively. The ethanol response of $\mathrm{TiO}_{2} / \mathrm{ZSM}-$ 5 sensor with the same concentration are found to be 11 , 44, 66 and 88 for 10, 100, 500 and 1000 p.p.m., respectively. It can be concluded that the response goes on increasing with increase in ethanol vapour concentration for both types of blended films. The study reveals that all sensor films can sense ethanol vapours with a minimum concentration of 10 p.p.m. It is found that $\mathrm{TiO}_{2} / \mathrm{ZSM}-5$ composite thick film sensor for $25 \% \mathrm{TiO}_{2}$ concentration can detect highly concentrated ethanol level of 2500 p.p.m. among all the composite sensors. The gas sensing parameters for these metal oxide blended zeolite composite sensors are summarized in table 1.

\section{Discussion}

It is known that the ZSM-5 zeolite structure consists of two intersecting sets of tubular channels formed by a 10membered ring of $\mathrm{TO}_{4}$ tetrahedra [5]. Therefore, most probable sites offered by peculiar well-aligned ZSM-5 structure for guest molecules are straight channels, sinusoidal channels and a region of channel intersection (a nearly spherical cavity of $8.7 \AA$ dia). Moreover, the internal microporosity of zeolites gives rise to high suface area, providing additional sites for adsorption of molecules to take place. In case of metal oxide blended ZSM-5 zeolites, metal oxides molecules, being nanoparticles, may occupy sites avialable inside the channels and also vacant sites availbale outside the channel, as shown in figure 9. As a result of incorporation of $\mathrm{ZnO}$ and $\mathrm{TiO}_{2}$ nanoparticles in any of these sites, the surface area of the metal oxide blended ZSM-5 sensors increases [12]. Upon exposure of ethanol vapours, ethanol molecules can spread into the well-aligned structure very effectively resulting in larger interactions. Therefore, $\mathrm{ZnO}$ as well as $\mathrm{TiO}_{2}$ blended ZSM-5 sensors show enhancement of ethanol sensitivity, which is shown in figure 9 .

In pure ZSM-5, the conductivity is only due to mobile cations. Water molecules, present in the cages and channels,

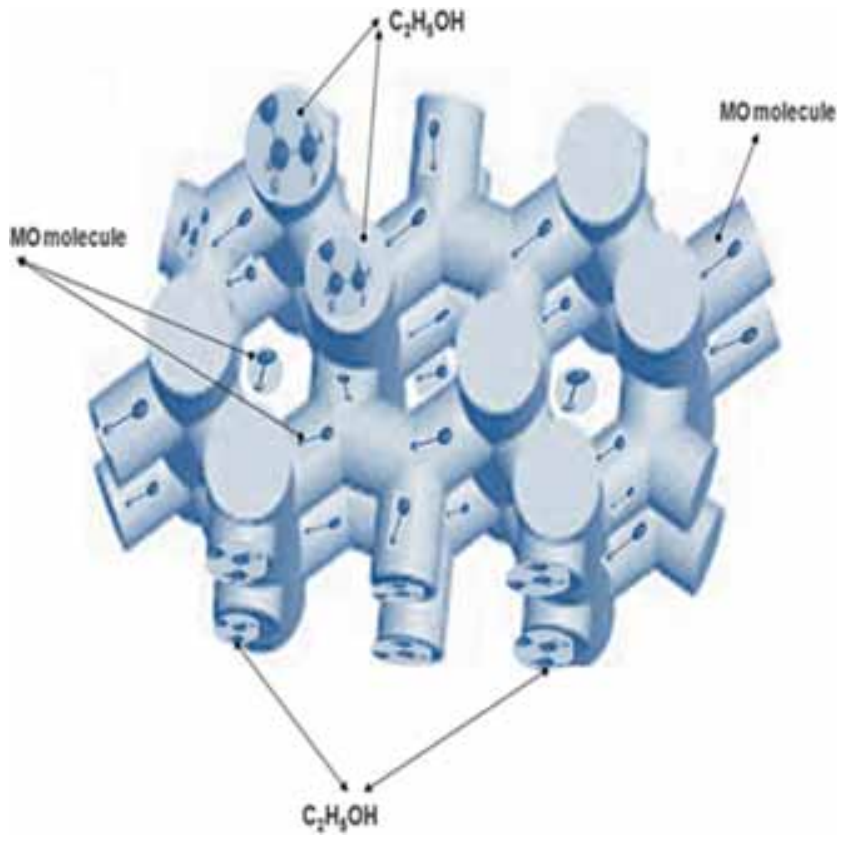

Figure 9. Schematic diagram of ZSM-5 zeolite channels with the incorporation of metal oxides $\left(\mathrm{ZnO} / \mathrm{TiO}_{2}\right)$ for ethanol sensing mechanism.

create hurdles for the motion of these cations. Therefore, conductivity is found to be low.

When $\mathrm{ZnO}$ or $\mathrm{TiO}_{2}$ nanoparticles are encapsulated in ZSM-5, they may interact with the water molecules present in the void space of ZSM-5 zeolite and lead to protonation as follows [28-30]:

$$
\begin{aligned}
& \mathrm{ZnO}+\mathrm{H}_{2} \mathrm{O} \longrightarrow \mathrm{Zn}^{2+}+2 \mathrm{OH}^{-}+\mathrm{H}_{2} \mathrm{O} \\
& \mathrm{TiO}_{2}+\mathrm{H}_{2} \mathrm{O} \longrightarrow \mathrm{TiO}_{2}+2 \mathrm{OH}^{-}+\mathrm{e}^{+}
\end{aligned}
$$

The interaction of water with $\mathrm{ZnO}$ surface results in partial dissociation of water molecule, resulting in $\mathrm{H}^{+}$and $\mathrm{OH}^{-}$ species. The molecular adsorption of water on $\mathrm{ZnO}$ can be clearly identified by the presence of absorption band at 1590 and $3683 \mathrm{~cm}^{-1}$ in FTIR spectra.

The formation of protons into the cages and channels of host ZSM-5 is equivalent to the $\mathrm{H}^{+}$form like zeolite structure. These protons may interact with the lone pair electron at 
the hydroxyl group of the ethanol, leading to increase in conductivity. In other words, $\mathrm{H}^{+}$mobility or hoping of $\mathrm{H}^{+}$from one site to other may be responsible for enhanced conduction in case of composite sensor.

Furthermore, the ethanol vapours may possibly interact with lattice oxygen in metal oxide via the following reaction [31]:

$\mathrm{C}_{2} \mathrm{H}_{5} \mathrm{OH}+6 \mathrm{O}_{2} \longrightarrow 2 \mathrm{CO}_{2}+3 \mathrm{H}_{2} \mathrm{O}+12 \mathrm{e}^{-}$

Thus, in case of metal oxide blended ZSM-5 composites, not only cations and protons but also chemically adsorbed oxygen lattice sites, interact with ethanol vapour molecules. Therefore, the ethanol sensitivity is found to be higher than pure ZSM-5 zeolite for all composite sensors.

The dependence of sensitivities and operating temperature on the concentration of metal oxides may be due to the number of adsorption sites present for ethanol adsorption at that specific temperature for a particular concentration. In case of $\mathrm{ZnO}$ blended samples, maximum sensitivity is observed for $50 \% \mathrm{ZnO}$ concentration. This may be due to the availability of sufficient ionic species of oxygen on the film surface along with protons which may interact most effectively with ethanol vapour molecules at that temperature. In case of $\mathrm{TiO}_{2}$, maximum sensitivity is observed for the highest $\mathrm{TiO}_{2}$ concentration $(75 \%)$. It may also be due to the availability of maximum adsorption sites at that concentration.

The gas upload capacity is determined by exposing the metal oxide blended sensor to variable concentrations of ethanol vapours. For a low ethanol concentration (10 p.p.m.), film surface area covered by the ethanol molecules is also small and hence the surface reactions between oxygen molecules, protons and ethanol molecules takes place slowly because of the availability of fewer number of ethanol molecules to react with and to get adsorbed. Increase in ethanol concentration results in increase in surface reaction due to larger surface coverage of ethanol molecules, which in turn leads to a rapid increase in ethanol response. On further increase in gas concentration, the surface coverage of ethanol molecules on the film begins to attain saturation. Hence, the response to ethanol saturates for higher ethanol concentrations.

Decrease in response time with increase in metal oxide concentration may also be related to availability of number of oxygen ion species to interact with ethanol molecules.

\section{Conclusions}

The introduction of $\mathrm{ZnO}$ and $\mathrm{TiO}_{2}$ into ZSM-5, by physical dispersion method, does not alter the basic structure of ZSM-5 zeolite. Blending ZSM-5 zeolite with metal oxides enhances the sensor response to ethanol. Concentration of blended metal oxides has strong influence on ethanol sensing parameters like operating temperature, active region and response/recovery behaviour. Response decreases with increase in $\mathrm{ZnO}$ concentration, while it increases with increase in $\mathrm{TiO}_{2}$ concentration. These novel composite sensors can detect ethanol gas with a minimum concentration of 10 p.p.m. Higher ethanol uptake capability is observed for $\mathrm{TiO}_{2}$ blended sensors than $\mathrm{ZnO}$ blended sensor. Introduction of metal oxides as reinforcing materials in ZSM-5 leads to fast response (to ethanol) and recovery. The study reveals that there is a strong influence of concentration of blended metal oxide materials on ethanol sensing behaviour of ZSM-5 zeolite.

\section{Acknowledgement}

This work was carried out under the Major Research Project (F. No. SR/S2/CMP-49/2009) funded by the Department of Science and Technology (DST), New Delhi, India.

\section{References}

[1] Yang S, Lach-hab M, Vaisman I I, Blaisten-Barojas E, Li X and Karen V L 2010 J. Phys. Chem. Ref. Data 39033102

[2] Xue Z, Ma J, Zheng J, Zhang T, Kang Y and Li R 2012 Acta Mater. 605712

[3] Sahner K, Hagen G, Schonauer D, Reis S and Moos R 2008 Solid State Ionics 1792416

[4] Shirazi L, Jamshidi E and Ghasemi M R 2008 Cryst. Res. Technol. 431300

[5] Lu R, Tangbo H, Wang Q and Xiang S 2003 J. Nat. Gas Chem. 1256

[6] Hagen G, Dubbe A, Rettig F, Jerger A, Birkhofer T, Müller R, Plog C and Moos R 2006 Sensor Actuat. B Chem. 119441

[7] Dubbe A and Moos R 2008 Sensor Actuat. B Chem. 130546

[8] Sazama P, Jirglová H and Dědeček J 2008 Mater. Lett. 624239

[9] Xu X, Wang J and Long Y 2006 Sensors 61751

[10] Zheng Y, Li X and Dutta P K 2012 Sensors (Basel) 125170

[11] Sun Y-F, Liu S-B, Meng F-L, Liu J-Y, Jin Z, Kong L-T and Liu J-H 2012 Sensors (Basel) 122610

[12] Zhang W, Bi F, Yu Y and He H 2013 J. Mol. Catal. A Chem. 3726

[13] Dighavkar C 2013 Arch. Appl. Sci. Res. 596

[14] Patil D R, Patil L A and Amalnerkar D P 2008 Bull. Mater. Sci. 30553

[15] Roy S, Saha H and Sarkar C K 2010 Int. J. Smart Sens. Intell. Syst. 3605

[16] Mahabole M P, Lakhane M A, Choudhari A L and Khairnar R S 2012 J. Porous Mater. 20607

[17] Cheng Y, Liao R H, Li J S, Sun X Y and Wang L J 2008 J. Mater. Process. Technol. 206445

[18] Dayan N J, Sainkar S, Karekar R and Aiyer R 1998 Thin Solid Films 325254

[19] Mene R U, Mahabole M P, Aiyer R C and Khairnar R S 2010 Open Appl. Phys. J. 310

[20] Khatamian M and Irani M 2009 J. Iran Chem. Soc. 6187

[21] Ming C and Wu P 2005 Chin. J. Geochem. 24370

[22] Karakassides M A 1997 Clays Clay Miner. 45649 
[23] Moreno-Piraján J C, Garcia-Cuello V S and Giraldo L 2010 J. Thermodyn. Catal. 11

[24] Nejati K, Rezvani Z and Pakizevand R 2011 Int. Nano Lett. 175

[25] Padilha R S, Ferrari-Lima A M, Seixas F L, Vagner R, Fávaro S L, Hioka N and Fernandes-Machado N R C 2013 Chem. Engg. Trans. 32823

[26] Senthilkumar K, Paul P, Selvaraju C and Natarajan P 2010 J. Phys. Chem. C 1147085
[27] Ba-Abbad M M, Kadhum A A H, Mohamad A B, Takriff M S and Sopian K 2012 Int. J. Electrochem. Sci. 74871

[28] Yimlamai I, Niamlang S, Chanthaanont P, Kunanuraksapong R, Changkhamchom S and Sirivat A 2011 Ionics (Kiel) 17607

[29] Zeng W, Liu T and Wang Z 2010 Mater. Trans. 51243

[30] Baruah S, Pal S K and Dutta J 2012 Nanosci. Technol. 290

[31] Daryakenari A A, Vaezi M R, Ebadzadeh T and Daryakenari M A 2012 Int. J. Phys. Sci. 72110 